\title{
Request Strategies in the TV Series Victorious
}

\author{
Windy Alviora Lestari*, Thomas Joko Priyo Sembodo \\ English Department, Universitas Gadjah Mada, Indonesia \\ *Email: windyalviora14@gmail.com
}

\begin{abstract}
This research aimed to investigate request strategies as found in an American TV series Victorious. In particular, it attempted to identify and classify request head acts, external modifications, and types of sentences of the requests expressed by the characters in the series. Therefore, utterances containing requests in the TV series were used as the data of this study. The results show that the most frequently used request strategy in the TV series was direct strategy (mood derivable) with 194 occurrences (67\%). In addition, an external modification by means of grounder was found to be the most frequent strategy in the TV series with 32 occurrences ( $94 \%$ of the total number of the external modifications). Furthermore, it was found that the imperative sentence was the most frequent type of sentence utilized by the characters in the series when making requests with 216 occurrences (74\%). In conclusion, the tendency for the characters to use mood derivable as their request strategy might due to their intimacy with each character and the informal situations and conversations where they interacted with each other throughout the TV series. In addition, the proclivity of the characters to use grounder may relate to ease and simplicity. Finally, the tendency of the characters to use declarative sentences when making requests might due to its simplicity and function to state facts, opinions, or ideas.
\end{abstract}

Keywords: external modifications; request strategies; types of sentences; victorious.

\section{INTRODUCTION}

Language has a crucial role in establishing communication. It is used by people to communicate their ideas to others in both written and spoken interactions. Verbal acts can be performed in a variety of situations, for example, face-to-face conversations, telephone calls, and other types of speech events. In this verbal communication, people often use speech acts which Finnegan (2012) describes as actions that are carried out through a language. One of these speech acts is a request, which is a face-threatening act. According to Brown and Levinson (1987), a face-threatening act is a verbal act that threatens either the negative or positive face of the hearer.

Searle (1969) defines a request as a directive form which is regarded as an attempt to get the hearer to do an act which the speaker wants the hearer to do (p. 66). For instance, when someone says "Can you make a cup of coffee for me please; I cannot go to sleep until it's done" the speaker performs an action of asking the hearer to make a cup of coffee for the speaker. This request consists of two main acts, which are the head act and its external modification.

The head act is the core or the main part of the request that has the function of expressing the request, and it can stand by itself. Blum-Kulka and Olshtain (1984) distinguish three request catagories reflecting the degrees of directness in the request, which are direct request, conventionally indirect request, and non-conventionally indirect request.

Request strategies can be found in fictional works that include movies and TV series spoken by characters in dialogues. In the case of this study, we 
selected an American TV series Victorious to study request stategies. This series is a sitcom series aired on Nickelodeon. The main goal of this research is to investigate requests produced by the characters of the series. We attempted to discover the request head acts and external modification strategies of the requests. In addition, we examine what types of sentences that the characters used in uttering the request strategies.

\section{LITERATURE REVIEW}

Request is an interesting topic that has attracted a large number of scholars to investigate it, some of which are directly related to the present research. For example, Yazdanfar and Bonyadi (2016) compare request strategies used by English and Persian speakers in their daily interactions. To this end, English and Persian TV series were observed and requestive utterances were transcribed. The utterances were then categorized based on BlumKulka and Olshtain's Cross-Cultural Study of Speech Act Realization Pattern for directness level and internal and external mitigation devises. According to the results, although speakers of both languages opted for the direct level as their most frequently used strategy in their daily interactions, the English speakers used more conventionally indirect strategies than the Persian speakers did, and the Persian speakers used more non-conventionally indirect strategies than the English speakers did. Furthermore, the analyzed data revealed the fact that American English speakers use more mitigation devices in their daily interactions with friends and family members than Persian speakers.

Another research by Rue and Zhang (2004) attempts to compare request strategies between two East Asian languages, Mandarin Chinese and Korean. The study is also methodologically significant, using naturally occurring conversational data rather than relying on written questionnaires, and taking multiple-turn sequences rather than isolated individual sentences, as the scope of analysis. However, while the goal of the study is to reveal real patterns and strategies in natural talk-ininteraction, some parts of the analysis are based solely on role-playing data. Given that communicative motivations in artificial role-playing can hardly be considered to be 'real,' this review concludes that more analysis should be based on the natural conversation to ensure authenticity in the discussion of request strategies.

Felix-Brasdefer (2005) investigated the request strategies used in a Mexican community, Tlaxcala, by examining the linguistic strategies and perceptions of politeness among male university students during refusal interactions in three politeness system: solidarity, deference, and hierarchy (Scollon and Scollon, 2001). Twenty male Mexican university students and all of them are native speakers participated in the study. The data were collected using open role-plays, supplemented by retrospective verbal reports during formal or informal interactions. The results of this empirical study showed that social factors such as power and distance play a crucial role in determining appropriate degrees of politeness in Mexican society.

Sari (2014) examines the requests used in the movie The Proposal. In particular, she attempts to identify and classify the request head acts and external modifications produced by the characters of the movie. The data used in this research are utterances containing request strategies. These data, then, are classified and analyzed using the theory of the request strategies proposed by Blum-Kulka and Olshtain (1984). The results show that there are 75 utterances containing request strategies, classified based on nine types of the request head acts and seven types of external modifications that modify the head acts. It is also found that direct request by means of mood derivable was the most preferred strategy in expressing request head act. Furthermore, precursors are the most commonly used external modification by the characters to attract the hearers' attention to fulfilling their requests.

Finally, Inayatin (2013) aims at identifying the types and frequencies of request strategies used by characters in the BBC miniseries Sense and Sensibility (2008) and analyzing how gender, social status, and age affect the realization of the requests produced by the characters in the series. The data were taken from characters' utterances. The characters' utterances were divided into 4 (four) categories based on same gender (male-male, female-female) and mixed gender (female-male, male-female) conversations. These data were then 
classified and analyzed using Blum Kulka et.al (1989) theory of request strategies. The research found three findings; first, characters of the same gender mostly use direct strategies rather than indirect strategies. First, indirect strategy among males, there are 8 requests found, while in indirect strategies only 2 requests are found. Female characters used 17 direct strategy requests while only using 14 indirect strategy requests. Second, request uttered by characters in mixed gender (female-male) interactions mostly use indirect strategies (5 requests) than direct strategies (2 requests). Lastly, requests uttered by characters in mixed gender (male-female) interactions tend to use direct strategies (9 requests) than indirect strategies (6 requests).

\section{THEORETICAL FRAMEWORK}

This research attempts to identify and classify request head acts, external modifications, and type of sentences that are used to express the requests. This study is in essence based on the taxonomy or theory proposed by Blum-Kulka \& Olshtain (1984). According to them, there are three directness levels of request, which are direct, conventional indirect and non-conventional indirect level of request strategies. Each of these types are broken down into smaller catagories. Under direct request strategy there are mood derivable (MD), explicit performatives (EP), hedged performatives (HP), locution derivable (LD), and scope stating (SS). Under conventionally indirect request strategies there are language specific suggestory formulae (LSSF) and reference to preparatory conditions (RTPC); and under non-conventionally indirect request strategy there are strong hints $(\mathrm{SH})$ and mild hints (MH).

Further more, the external modifications of the request strategies were studied by using the taxonomy proposed by Blum-Kulka, House and Kasper (1989). An external modifications can be present either before or after a head act (request), and it can be used as a supportive motive to mitigate the illocutionary force of the request. Or in other words, the external modification may be able to redude the threats resulting from the request (head act). As a result, it is expected that the hearer will be more likely to comply wih the request. According to Blum-Kulka, House, and Kasper (1989), there are six types of external modifications: preparator (PR), grounder (GR), disarmer (DIS), sweetener (SWT), imposition minimizer (IM), and promise of reward (PoR).

With regard to the types of sentences, a sentence can be defined as a group of words which is complete in itself as the expression of a thought, and usually it has a subject and a verb(s). Sentences can be classified into their functions or purposes. According to Shewan and Moes (1996), there are four types of sentences that are declarative (DS), imperative (ImS), interrogative (InS), and exclamatory sentences (ES).

\section{METHODS}

The data source for this study was the TV series Victorious season one that consists of 19 episodes. Victorious was an American situational comedy created by Dan Schneider which aired from March 27th 2010 to February 2nd 2013 on Nickelodeon.

The story of the series revolved around Tori Vega, a teenager who unintentionally attended Hollywood Arts High School after taking her sister's place, Trina Vega, in an audition to enter the school. There, she met many people such as Andre Harris, a genius musician who later became her best friend throughout the sitcom along with Robbie Shapiro, a teenager who always brought his puppet, Rex Powers, and treated it like a human being, Jade West, a girl who always wore black and was feared by all students in Hollywood Arts High School and turned out to have a handsome boyfriend, Beck Oliver, who confused to socialize with everybody, and Cat Valentine, an innocent teenager who always told stories about her unfortunate brother.

The data collected for this research were 279 utterances made by the characters in Victorious which contain request strategies and external modifications. In order to watch the entirety of Victorious season one, we watched the entire season through subscription service for watching TV episodes and movies, iFlix. In collecting the data, we made use of the TV series' subtitles that are available on https://isubtitles.in/victorious-subtitles. 
In order to collect the data, we watched each episode of the TV series from iFlix with a web browser to get comprehensive understanding of the storyline of each episode and to make sure that the subtitles matched the words spoken in all conversations/dialogues in all the episodes. Subsequently, we re-watched each episode from iFlix with a web browser to identify and made a list of the data (the request strategies and external modifications) from each episode. Finally, we identified those containing external modifications and copy-pasted them on another list.

In analyzing the data, the collected data were classified according to strategies proposed by BlumKulka and Olshtain (1984). We listed all of the request head acts based on the request strategies depending on their levels of directness, which are direct, conventionally indirect, and nonconventional indirect. In addition, the collected data were identified whether or not they were uttered with external modifications. The data containing external modifications were then selected and put into a separate list without erasing them from the main list. This was done as the first step in analyzing the external modifications. Subsequently, the request strategies were classified based on the external modification taxonomy proposed by Blum-Kulka, House and Kasper (1989) that consist of preparator, grounder, disarmer, imposition minimizer, sweetener, and promise of reward.

\section{RESULTS AND DISCUSSION}

\section{Request Strategies}

The most frequent type of request head act used in the conversations/dialogues in the TV show was Direct Strategy with 178 occurrences (67\%), followed by Conventionally Indirect Strategy with 67 occurrences (26\%). Non-Conventionally Indirect Strategy is the least frequently used type of Request Head Act, occurring only 22 times throughout the first season of the TV show. For Direct Strategy, the most preferred sub-strategy used in the TV series according to the table 1 above is Mood Derivable with 146 occurrences. As for Conventionally
Indirect Strategy, Reference to Preparatory Condition sub-strategy was preferred more than Language Specific Suggestion Formulae. There were 22 Non-Conventionally Indirect Strategies that were identified in the data.

Table 1. Frequency of request strategies

\begin{tabular}{|c|c|c|c|c|}
\hline No & Head Acts & Type of Request & No & $\%$ \\
\hline 1 & \multirow[t]{9}{*}{ Direct } & Mood Derivable & 163 & 56 \\
\hline \multirow[t]{2}{*}{2} & & Explicit & 1 & - \\
\hline & & Performative & & \\
\hline \multirow[t]{2}{*}{3} & & Hedge & 1 & - \\
\hline & & Performative & & \\
\hline \multirow[t]{2}{*}{4} & & Locution & 10 & 4 \\
\hline & & Derivable & & \\
\hline \multirow[t]{2}{*}{5} & & Scope Stating & 19 & 7 \\
\hline & & SUB TOTAL & 194 & 67 \\
\hline \multirow[t]{4}{*}{6} & \multirow{7}{*}{$\begin{array}{l}\text { Conventional- } \\
\text { ly Indirect }\end{array}$} & Language & 14 & 5 \\
\hline & & Specific & & \\
\hline & & Suggestion & & \\
\hline & & Formula & & \\
\hline \multirow[t]{4}{*}{7} & & Reference & 55 & 21 \\
\hline & & Preparatory & & \\
\hline & & Conditions & & \\
\hline & & SUB TOTAL & 69 & 26 \\
\hline 8 & \multirow{5}{*}{$\begin{array}{l}\text { Non- } \\
\text { Conventional- } \\
\text { ly Indirect }\end{array}$} & Strong Hints & 31 & 8 \\
\hline \multirow[t]{4}{*}{9} & & Mild Hint & - & - \\
\hline & & & & \\
\hline & & SUB TOTAL & 31 & 7 \\
\hline & & TOTAL & 293 & 100 \\
\hline
\end{tabular}

\section{Mood Derivable}

(1) $\quad[00: 19: 17 \rightarrow 00: 19: 26]$ EP 5

Context: Jade, accompanied by Tori, is sitting in front of Beck's RV to give a present (a dog) to him. Jade checks to see whether Beck is asleep and asks Tori to give her the dog.

Jade: Beck's asleep. Give me the dog.

Tori: Okay. Oh wait, he has a runny nose.

Jade: Dogs don't know how to blow their nose.

In the dialogue above, Jade utters a request (in bold) that is categorized as a mood derivable. In addition, the request is in the form of an imperative sentence. This is marked by the verb present in the beginning of the sentence. In the sentence, Jade directly asked Tori to hand the dog to her because she wants to give it to Beck. Direct request sometimes can be classified as an impolite 
expression. However, in the conversation above, the request can be regarded as a polite request because Jade and Tori are friends and they are of the same age and that the situation of the conversation does not involve any negative emotions such as anger or resentment. Therefore, such a request strategy is appropriate in the context of the dialogue between the two characters.

\section{Locution Derivable}

$$
[00: 16: 27 \rightarrow 00: 16: 45] \text { EP } 7
$$

Context: The guidance counselor, Mr. Lane, comes to talk to Cat about her addiction on buying things from SkyStore.

\section{Mr. Lane: Cat, I think we need to talk about this, cause...}

Cat: See this filthy icky tennis ball?

Mr. Lane: Yeah.

Cat: Look it, fresh as a daisy.

In the conversation above, Mr. Lane's utterance to Cat can be classified under locution derivable request category in that his utterance contains a word (need) that indicates an obligation. As it has been mentioned earlier, a locution derivable request can contain a word of phrase indicating an obligation, such as have to or got to. Although Mr. Lane's request does not contain either of the phrases, it contains the word 'need' that seems to indicate an obligation word. In addition, the context of this conversation explains that Cat's addiction to online shopping has gotten worse. She has bought a large number of unnecessary items from an online store called SkyStore. In this conversation, it is shown that Cat has bought a tennis ball washer even though she does not play tennis. Seeing this, as a counselor, Mr. Lane thinks that it is necessary for him to talk to Cat about her worsening addiction.

(3) $[00: 05: 50 \rightarrow$ 00:05:57] EP 7

Context: Robbie and Rex are watching Robbie's interview with Shinjin. However, Rex sees Tori in the background doing something that seems interesting. Subsequently, Robbie asks Rex to focus on his interview, and Rex asks Robbie replay the video.

Rex: Look, you see Tori in the background.

Robbie: You're supposed to be focusing my interview with Shinjin.

Rex: Shut up, ding bat. Rewind the video, kill the volume, zoom in on Tori, and play it again.

In the example above, the request uttered by Robbie indicates his desire for Rex to focus on his interview rather than focusing on Tori who is in the background. Robbie and Rex are looking at Robbie's interview for The Slap, and Rex sees something more interesting that is Tori in the background squeezing her pimple. Rex then tells Robbie to notice Tori, and Robbie gets upset because of this as he thinks that Rex is not paying attention to his interview. Robbie's request can be categorized as another locution derivable. As mentioned earlier, a locution derivable request usually contains the phrase 'have to' or 'got to'. However, it is shown that Robbie's request does not contain either of the phrases. Instead, he uses the expression "you are supposed to" that suggests that Rex has to focus on Robbie's interview.

\section{Language Specific Suggestory Formulae}

$$
\text { [00:13:30 } \rightarrow \text { 00:13:33] EP } 6
$$

Context: Trina and Cat are on their way to Bakersfield to buy a solvent to wipe off her monster makeup. While Trina is driving, she applies lip gloss and Cat asks her to pull over.

(a) Cat: Trina, maybe you should pull over if
you're gonna put on lip gloss. (b) Trina: Maybe you should talk less.

Cat: That's what my dad always says.

In the example above, the requests can be categorized as language-specific suggestory formulae. These two requests contain the phrase 'you should' to indicate the use of this sub-strategy. In example (4a), Cat suggested that Trina pull over if she wants to put on some lip-gloss due to the obvious danger of not paying attention to the road. As shown in example (4b), Trina, who does not like to be told by Cat because Trina thinks that Cat is naïve and 
sometimes slow and finds it embarrassing to be told by someone like this, asks Cat to be quiet because she annoys her.

\section{Reference to Preparatory Conditions}

\section{(5) $\quad[00: 01: 22 \rightarrow 00: 01: 26]$ EP 2}

Context: Tori is in the hallway struggling to put all of her books into her locker. Andre and Robbie then come into the hallway talking about something. Andre sees Tori in the hallway then greets her. Tori asks Andre to help her put all of her books into their locker.

Andre: Hey, look who's here.

Tori: Hey, can you guys help me?

Andre: Sure.

The speaker in example (21), Tori, indicates the use of reference to preparatory condition as Tori uses a question with the word 'can' when she utters her request. The request in example (21) is made by the speaker (Tori) to her friends (Robbie and Andre) to help her put her books into the hearers' lockers as her locker is already full and the books keep falling down from her locker. In other words, by making a question asking the hearers' ability using the modal verb 'can', the speaker actually makes a request and not just asking the hearers' ability to help her with her books.

\section{Strong Hint}

(6) $\quad[00: 02: 24 \rightarrow 00: 02: 36] \mathrm{EP} 2$

Context: Andre and Robbie are in the hallway showing their locker to Tori. Suddenly, Mr. Lane, the school counselor comes to them and mentions about the squirrel in his office. They understand that Mr. Lane wants them to help him catch the animal.

Lane: Hey, Andre, Robbie! That squirrel's back in my office again.

Andre: I'll get the net.

Robbie: I'll get the nuts.

In the dialogue above, Mr. Lane's utterance can be classified as a request with a strong hint because he indirectly makes a request to Robbie and Andre to catch a squirrel from his office by using strong signal that can be understood easily by the hearers (Robbie and Andre). In this example, Mr. Lane does not ask or request Robbie and Andre directly to catch a squirrel in his office, such as with "Andre, Robbie, help me catch a squirrel in my office please" or "I want both of you to catch a squirrel in my office". Instead, Mr. Lane only utters the request with a partial reference that is "that squirrel's back in my office". This type of request strategy expects the hearer to undertand the speaker's intended meaning that is a request. In example [25], both Andre and Robbie understand the intended meaning of Mr. Lane, so that their responds are relevent to Mr. Lane's request. They say that they will get a net and some nuts to catch the squirrel. In other words, the hinted request of the speaker is successfully performed and understood by the hearer.

\section{External Modification}

There were only two types of external modifications strategies found in the TV series. The most frequent external modification that was used by the characters is grounder. There are 32 grounders or $94 \%$ of a total number of 34 external modificationns found in Victorious. The second type of external modification found in the TV series is imposition minimizer, which only occurred two times.

Table 2. Frequency of external modifications

\begin{tabular}{|c|c|c|c|}
\hline No & External Modifications & Total & $\%$ \\
\hline 1 & Preparator & - & \\
\hline 2 & Grounder & 32 & 94 \\
\hline 3 & Disarmer & - & - \\
\hline 4 & Sweetener & - & - \\
\hline 5 & Imposition minimizer & 2 & 6 \\
\hline \multirow[t]{2}{*}{6} & Promise of Reward & - & - \\
\hline & TOT & 34 & 100 \\
\hline
\end{tabular}

\section{Grounder}

(7) $\quad[00: 22: 42 \rightarrow 00: 22: 48]$ EP 5

Context: Jade and Beck finally got back together. They finally kissed and there was Tori behind them. It was getting awkward and she knew that she could 
ruin the moment but she needs Jade's help to drive her home.

Tori: Hey, um, it's getting kinda late. So, I was wondering if maybe you could drive me home?

Jade: It's not that far a walk.

The bold-faced part of Tori's utterance above is one example of an external modification (a grounder) that is present before a request. Tori makes a request to Jade to take her home as the evening is getting late. Tori utters this grounder as if to make her request more likely to be acted upon by the hearer (Jade). In addition, it can be argued that Tori expesses this type of external modification to lessen the force of her request as at that time Beck and Jade finally resume their relationship. Tori undestands that it is the time when they want to focus on each other, but she cannot help herself to go home as soon as possible because the night is getting late. Therefore, she adds a grounder to her request to lessen the force of her request.

\section{Imposition Minimizer}

$$
[00: 05: 59 \rightarrow 00: 06: 06] \text { EP } 3
$$

Context: Trina and Robbie are paired up to be each other's partner for an audition. Trina is embarrassed by the fact that her partner is Robbie because everybody at school thinks that he is weird as he always brings his puppet, Rex, to school. When it is about time for them to go to the audition, the teacher asks Robbie to put Rex down. He hesitates at first because he feels sorry that he has to leave Rex. Rex tells Robbie that he can leave Rex alone as long as he puts him down next to a particular girl.

Teacher: Leave the puppet.

Rex: Hey, it's cool. Just set me down next to the hot blonde.

The expression "Hey, it's cool" in the example above can be identified as an external modification of a request, and it belongs to the catagory of imposition minimizer. In this utterance, the speaker expresses the external modification before the head act (request). With this imposition minimizer, the speaker seems to try to minimize the feeling of being forced or imposed to coply with the sepaker's request. In the dialogue above, Robbie was not allowed to bring Rex to the audition, so the teacher asks him not to bring Rex to the audition. Knowing that Robbie was upset because he cannot bring Rex, Rex assures him that it is alright for Robbie to leave him by saying "It's cool". It implies that Robbie did not have to worry about Rex and just go to his audition without him as long he puts Rex down next to a girl described as "the hot blonde".

Table 3. Frequency of sentence types

\begin{tabular}{|r|l|r|r|}
\hline No & \multicolumn{1}{|c|}{ Sentences } & \multicolumn{1}{c|}{ No } & \multicolumn{1}{c|}{$\%$} \\
\hline 1 & Declarative & 47 & 16 \\
\hline 2 & Imperative & 216 & 74 \\
\hline 3 & Interrogative & 30 & 10 \\
\hline 4 & Exclamatory & - & \\
\hline \multicolumn{2}{|r|}{ TOTAL } & 293 & 100 \\
\hline
\end{tabular}

\section{Types of Sentences}

\section{Declarative Sentence}

$$
[00: 18: 20 \rightarrow 00: 18: 26] \text { EP } 8
$$

Context: Cat is still with some boys she has met on a beach. However, she then realizes that she has spent too much time with the boys, and she should go back to her friends. Then, the boys ask her to stay.

Cat: But I really should be getting back to my friends.

Boy 1: Oh, you can't leave now. Paul just made tuna tartare.

Boy 2: We caught the tuna this morning.

Boy 3: You gotta stay for the tuna tartae. Have some tuna.

The bold-faced part of the utterance in the dialogue above is an external modification of a request. This is a sentence that can be catagorized as a declarative sentence. This type of sentence is the most frequently used in the external modifications found in the TV series. The sentence "Paul just made tuna tartare" consists of a subject (Pul), a verb (made), and an object (tuna tartare). In the situation above, Cat is about to leave the boys because she has been out for too long and is worried that her friends will start looking for her. But Boy 1 stops her and informs her to join them because one of his friends, Paul, has just made a meal for them. 


\section{Imperative Sentence}

(10) $[00: 08: 00 \rightarrow$ 00:08:18] EP 17

Context: Tori was shooting for The Wood and started to introduce herself but her phone rang in the middle of the shooting. Then, Kyle asked her to answer it.

Tori: Hey, I'm Tori Vega. I live here in the Hollywood Hills with my mom, dad, and my big sister, Trina.

Kyle: Keep goin'.

Tori: All right. Let's see. And there's my phone.

Kyle: Answer it.

Tori: Okay.

In the dialogue above, Kyle's utterances, "Answer it" and "Keep goin" are clearly an imperative sentence. Unlike the declarative sentence, the imperative sentence does not need a subject like an example above. In these examples, the speaker, Kyle, begins each of her utterances with a verb, 'keep' and 'answer'. Imperative sentences do not rquire a subject because the subject already exists implicitly. The subject which is used in an imperative sentence is "you", the hearer. In addition, the imperative sentences above contains bare infinitives as their verbs (keep and answer). Bare infinitive is a verb that is not added by anything, such as an "s" or "es".

\section{Interrogative Sentence}

$$
\text { [00:17:05 } \rightarrow \text { 00:17:18] EP } 4
$$

Context: Trina is having an argument with Tori about her birthday present. She sees Tori holding a cup of coffee and it seems like Tori has not drunk the coffee at all. Then, Trina implicitly asked Tori to give her coffee to Trina.

Tori: Trina, how can you just do that? You can't...

Trina: Go to scamper. Hey, are you gonna finish your coffee?

Tori: No. Jade found this in the... you can have it.

The sentence "Hey, are you gonna finish your coffee?" is an indirect request that is expressed in an interrogative sentence. A yes-or-no question (interogative) is formed by exchanging the subject and auxiliary positions or connecting the verb 'be'. In other situations, if there is only the main verb in the sentence, the sentence begins with 'do', 'does', or 'did'.

\section{CONCLUSION}

This research investigated request head acts and external modifications expressed by the characters in the TV series Victorious season 1, episodes 1-19. The data were identified and classified using the taxonomy of request strategies proposed by BlumKulka and Olshtain (1984) and Blum-Kulka, House and Kasper (1989) respectively.

The findings revealed that 263 utterances containing requests were produced by the characters in the TV series. This research found that the most frequently used type of request head act among the characters in the TV series was a direct strategy. Due to the intimate relationships among the characters, the use of direct strategy may show the closeness or intimacy between the characters rather than impolite or rude expression. The second possible cause as to why the use of direct strategy was most frequent might due to the facts that almost all of the dialogues taking place throughout the TV series were in informal situations. The scenes on the TV series mainly involved the conversations between people of the same age, teachers, and family members.

In addition, a number of the requests (head acts) were accompanied with external modifications that function to prepare the hearer for the request, prevent refusals, draw the interlocutor's attention, justify the request, or facilitate negotiation among the interlocutors. The research found that there were 34 requests, each of which was either followed or preceded by an external modification. The research found that that grounder was the most frequent external modification used by the characters in the TV series to modify their request with a total of 32 occurrences. Most of them were used for major requests, such as asking the hearer to help clean the speaker's gum, lend money, or to drive the speaker home when the night was getting late. 
Furthermore, requests and their external modifications can be classified into types of sentences. There are four types of sentences based on their functions, which are declarative, imperative, interrogative, and exclamatory sentence. The research found that imperative sentence was the most frequent type of sentences used by the characters in making requests and external modifications (233 occurences). The tendency of the characters to use the imperative to utter requests might due to its directness and simple form.

\section{REFERENCES}

Blum-Kulka, S., \& Olshtain, E. (1984). Requests and apologies: A cross-cultural study of speech act realization patterns (CCSARP). Applied

Linguistics, 5(3), 196-213.

doi:10.1093/applin/5.3.196

Blum-Kulka, S., House, J. \& Kasper, G. (1989). Cross-cultural pragmatics: Requests and apologies. Norwood, NJ: Ablex.

Brown, P. \& Levinson, S. (1987). Politeness: Some universals in language usage. Cambridge: Cambridge University Press.

Félix-Brasdefer, J. C. (2005). Indirectness and politeness in Mexican requests. In D. Eddington (ed..), Selected proceedings of the 7th Hispanic linguistics symposium. (pp. 6678). Somerville, MA: Cascadilla Proceedings Project.

Finegan, E. (2012). Language: Its structure and use ( $6^{\text {th }}$ ed.). Boston MA: Wadsworth.
Inayatin, A. (2013). The requests strategies as found in Sense and Sensibility movie: $A$ sociooragmatic analysis. (Unpublished undergraduate thesis). Universitas Gadjah Mada, Yogyakarta, Indonesia.

Rue, Y. \& Zhang, G. (2008). Request strategies: A comparative study in Mandarin Chinese and Korean. Amsterdam: John Benjamin. doi:10.1075/pbns.177.

Sabater, S. R. (2011). Interlanguage Pragmatic Development: The Study Abroad Context by SCHAUER, GILA A. The Modern Language Journal, 95(2), 333-334. doi:10.1111/j.15404781.2011.01199.x

Sari, D. W. (2014). The Use of Request Strategies in the Movie The Proposal. (Unpublished undergraduate thesis). Universitas Gadjah Mada, Yogyakarta, Indonesia.

Schneider, D. (Writer). (2010). Victorious [Television series]. California, United States: Nickelodeon. Retrieved December 12, 2017, from https://piay.iflix.com/

Scollon, R. \& Scollon, W. (2001). Intercultural Communication: A discourse approach (2nd ed.). Malden, MA: Blackwell.

Shewan, E. \& Moes, G.J. (1996). Basics of communicaing effectively. Arlington Heights: Christian Liberty Press.

Searle, J. (1969). Speech acts. Cambridge: Cambridge University Press.

Yazdanfar, S. \& Bonyadi, A. (2016). Request strategies in everyday interactions of Persian and English speakers. SAGE Open, OctoberDesember, 1-11. doi: $10.1177 / 2158244016679473$ 